\title{
MORAL DILEMMAS AND REOUIRING THE IMPOSSIBLE
}

By: Terrance C. McConnell

McConnell, Terrance C. "Moral Dilemmas and Requiring the Impossible," Philosophical Studies 29(5) (June 1976), pp. 409-413.

Made available courtesy of Springer Verlag.

The original publication is available at www.springerlink.com

***Note: Figures may be missing from this format of the document

\section{Article:}

It can be shown that the conjunction of three theses, each of which has been maintained by some philosophers, is inconsistent. The first thesis is that there are genuine moral dilemmas. Moral dilemmas are typically described in the following way: an agent is in a situation such that he ought to do each of two actions both of which he cannot do. For example, he ought to do $A$ and he ought to do $B$, but he cannot do both $A$ and $B$. (It is obvious that if there are genuine moral dilemmas, then the 'oughts' that conflict must be strict or absolute ones, and not merely prima facie ones.) We may represent such a situation in this way:
(1) $O A$
(2) $O B$
(3) $-\diamond(A \& B)$

That 'ought' implies 'can' is the second thesis and it may be represented as

$$
(X)(O X \rightarrow \diamond X)
$$

The third thesis is that the following well-accepted distribution principle of deontic logic holds:

$$
(O A \& O B) \leftrightarrow O(A \& B)
$$

It follows from (1) and (2) that

$$
O A \& O B
$$

One can then derive

$$
\text { (7) } \quad O(A \& B)
$$

from (5) and (6). Since (4) holds for any action, we may conclude that

$$
O(A \& B) \rightarrow \diamond(A \& B)
$$

But in a genuinely dilemmatic situation the consequent of (8) is false, as is indicated by (3). It follows, then, by modus tollens that

$$
\text { (9) } \quad-O(A \& B)
$$

Since (7) and (9) are contradictory, the conjunction of the three theses in question is inconsistent. At least one must be given up, but which? 
In a recent paper ${ }^{1}$ Bas C. Van Fraassen argues that there are moral dilemmas (pp. 9-11) and that as a result the distribution principle, (5), must be relinquished (p. 15). Let us grant, strictly for the sake of argument, that there are genuine moral dilemmas. An opponent might still ask, "Why give up (5) instead of (4)?" Van Fraassen has an answer to this. He gives an argument (p. 13) that can be construed as a defense of the principle that 'ought' implies 'can'. He argues that if one were required to do the impossible (for example, if one were required to do both $A$ and $B$ in a dilemmatic situation) then one would be required to do everything, and hence all moral distinctions would collapse. It would no longer be the case that some things are obligatory, some forbidden, and some merely permissible. Rather, everything would be obligatory. But surely, the argument goes, it is not the case that for a person in a quandary all moral distinctions collapse. Since it is not plausible to say that an agent may in some cases be required to do the impossible, 'ought' must imply 'can'. This argument is very interesting, but Van Fraassen does not demonstrate how being required to do the impossible entails that everything is obligatory. Since being required to do the impossible is not in itself contradictory, it is not at all clear why such a conclusion would follow.

There is a way, however, of constructing an argument to show that if one were required to do the impossible in dilemmatic situations then one would be required to do everything, ${ }^{2}$ and since Van Fraassen accepts the most crucial and controversial principle employed in the proof this is probably the argument that he has in mind. He states (p. 15) that the following rule holds ${ }^{3}$

$$
\square(A \rightarrow B) \rightarrow(O A \rightarrow O B)
$$

The following is a legitimate instance of rule (10):

$$
\square((A \&-A) \rightarrow B) \rightarrow(O(A \&-A) \rightarrow O B) .
$$

Since the antecedent of $(11), \square((A \&-A) \rightarrow B)$, is true, one can apply modus ponens and derive

$$
O(A \&-A) \rightarrow O B)
$$

Ordinarily it is thought that one in a moral dilemma is required to do and not do the same action. That this result follows from dilemmatic situations, described by (1), (2), and (3), can be shown. From (3), by a simple modal transformation and the commutative principle, it follows that

$$
\square-(B \& A)
$$

And from (13) we may derive

$$
\square(B \rightarrow-A) .
$$

The following is an instance of rule (10):

$$
\square(B \rightarrow-A) \rightarrow(O B \rightarrow O-A) .
$$

From (14) and (15) it follows that

$$
O B \rightarrow O-A
$$

Another application of modus ponens with (2) and (16) entails

$$
O-A \text {. }
$$

Conjoining (1) and (17), one gets

$$
O A \& O-A .
$$


So in dilemmatic situations the same action is obligatory and forbidden. Both Van Fraassen (p. 15) and his opponent will accept (18), but for the opponent

$$
O(A \&-A)
$$

will also hold, since it follows from (18) by (5). Given (19), we can see why some (viz., Van Fraassen's opponent) say that in dilemmatic situations one is required to do the impossible. But now we can see what Van Fraassen's argument will be. Since (11) and (12) hold for any B, Van Fraassen's opponent will be committed to the truth of

$$
O B \text {, for any } B
$$

since it follows from (12) and (19). So if one claims that there are genuine moral dilemmas, that (5) holds, and that as a result one has a counter-example to the principle that 'ought' implies 'can' (and this is what Van Fraassen's opponent holds), one will be committed to the view that when an agent is in a moral dilemma everything is obligatory for him. Since this is clearly counterintuitive, 'ought' must imply 'can' and (5) must be given up.

Van Fraassen's opponent will surely want to deny that he is committed to such a view. What he might do, then, is question the plausibility of (10) or (11). One can assign truth-values to the variables in (11) to make the antecedent true and the consequent false. ${ }^{4}$ The antecedent must be true since $(A \&-A)$ is necessarily false. For the consequent, one may assign to $O(A \&-A)$ the value true and to $O B$ the value false. Van Fraassen's opponent, at least, will grant that in dilemmatic situations $O(A \&-A)$ is true and for some values of $B, O B$ is false. (His wanting to say the latter is precisely what gives Van Fraassen's argument its apparent force.) Given this assignment of truth-values, it looks like we have a counter-example to (11). If we do, Van Fraassen's argument will be inadequate since it depends on both (10) and (11).

What Van Fraassen must do is claim that the apparent counterexample to (11) is not a genuine one. But how can he defend this view? The antecedent of (11) must be true, and Van Fraassen certainly will not want to say that $O B$ (for any $B$ ) must always be true. So what he must say is that $O(A \&-A)$ can never be true. If it cannot be true the consequent of (11) cannot be false, and so (11) itself cannot be false. Van Fraassen's opponent, however, claims that $O(A \&-A)$ can be true. Notice, though, what is being affirmed (or denied) when one asserts (or rejects) $O(A$ $\&-A)$. To say that $O(A \&-A)$ can be true is to say that the impossible can be required. To claim that it can never be true is to claim that the impossible cannot be required. So whether the alleged counterexample is a genuine or not depends solely on whether or not the impossible can be required. Fortunately we do not have to answer this question in order to assess Van Fraassen's argument. We are now in a position to show that (11) cannot be legitimately used to prove that the impossible may not be required. (11) is true only if the impossible cannot be required; to use (11) to show that the impossible cannot be required simply begs the question.

So even if one grants Van Fraassen that there are moral dilemmas, he has not shown that (5) must be given up. We know that at least one of the three theses must be dropped, but which is still an open question.

\section{Notes}

1. Bas C. Van Fraassen, 'Values and the Heart's Command', The Journal of Philosophy LXX (1973), 5-19. All page references to this paper will be given parentically in the text.

2. That Van Fraassen might have in mind an argument similar to the one that I go on to sketch was first suggested to me by Professor Norman Dahl.

3. It is not clear whether Van Fraassen wants this rule with the necessity operator or without it. It will be evident, however, that what I have to say against his argument will hold whether the rule is stated with or without the operator. It will also be evident, I think, that the rule stated with the necessity operator is the more plausible of the two.

4. This possible counterexample was first suggested to me (in another context) by Professor Burnham Terrell. 